\title{
Ultrasound treatment for accelerating fracture healing of the distal radius. A control study ${ }^{1}$
}

\author{
Yinwen Liu', Xiaoen Wei", Yong Kuang ${ }^{\mathrm{III}}$, Yuxin Zheng ${ }^{\mathrm{IV}}$, Xinfeng Gu ${ }^{\mathrm{V}}$, Hongsheng Zhan ${ }^{\mathrm{VI}}$, Yinyu Shi ${ }^{\mathrm{VII}}$ \\ DOI: http://dx.doi.org/10.1590/S0102-86502014001800012
}

${ }^{\mathrm{I}}$ Master of Medicine, Doctor, Institute of Shuguang Hospital Affiliated to Shanghai TCM University, Shanghai, China. Design of the study, acquisition of data.

IIDoctor of Medicine, Institute of Shuguang Hospital Affiliated to Shanghai TCM University, Shanghai, China. Design of the study, acquisition of data. IIIDoctor of Medicine, Institute of Shuguang Hospital Affiliated to Shanghai TCM University, Shanghai, China. Design of the study, manuscript writing. ${ }^{\text {IV }}$ Master of Medicine, Institute of Shuguang Hospital Affiliated to Shanghai TCM University, Shanghai, China. Design of the study, acquisition of data. ${ }^{\mathrm{v}}$ Master of Medicine, Doctor, Institute of Shuguang Hospital Affiliated to Shanghai TCM University, Shanghai, China. Design of the study, critical revision.

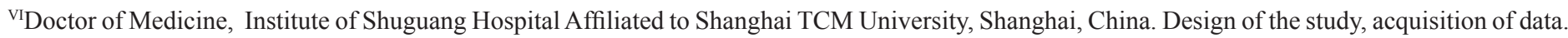
${ }^{\mathrm{VII}}$ Master of Medicine, Doctor, Institute of Shuguang Hospital Affiliated to Shanghai TCM University, Shanghai, China. Manuscript writing, critical revision.

\section{ABSTRACT}

PURPOSE: To investigate the accelerating effects of low-intensity pulse ultrasound stimulation (LIPUS) on the fracture healing of distal radius.

METHODS: A total of 81 patients with distal radius fracture were randomly divided into two groups: the ultrasound treatment group and the control group. Patients in the ultrasound treatment group were immobilized in a below-elbow cast and received LIPUS treatment $15 \mathrm{~min} /$ day, while the control group were immobilized by a plaster support and cast. The patients were followed up every week and took X-ray films. The initial and healed X-ray films and the gray value of fracture site were analyzed by Photoshop software. The effect of reposition was evaluated based upon Steward recommended by Dienst, combining with Aro's measuring method.

RESULTS: Clinical fracture healing time in ultrasound group was significantly shorter than that in the control group $(32.04 \pm 2.58 \mathrm{~d}$ vs. $40.75 \pm 5.12 \mathrm{~d}, \mathrm{p}<0.01)$. In addition, the grey value changes of fracture sites of the ultrasound group were much higher than that of the control group. The reposition effects of fracture healing had no difference between the two groups $(p>0.05)$.

CONCLUSION: Low-intensity pulse ultrasound stimulation could accelerate fracture healing of the distal radius and promote local bone formation.

Key words: Ultrasonography. Radius Fractures. Fracture Healing. Osteogenesis. 


\section{Introduction}

Fracture healing is a homeostatic process that is depends on many factors, including specialized cell activation and bone immobility during repair ${ }^{1}$. About $5 \%-10 \%$ of fractures lead to delayed union (even nonunion) and require corrective secondary surgery because of the impairments in healing process ${ }^{2,3}$. Various physical and biologic methods are developed for enhancing fracture healing including, laser, direct current, microcurrent, ultrasound, electrical magnetic field, and capacitive coupled electrical stimulation ${ }^{4-6}$. Low-intensity pulsed ultrasound (LIPUS) is a form of ultrasound that transmitted into connective tissues as an acoustic wave. As a non-invasive therapy, LIPUS has been used to promote fracture healing for 30 years, and is studied and applied in many clinical studies ${ }^{7-9}$.

LIPUS can stimulate the differentiation of bone-forming cells which contribute to bone formation, fracture healing and recovery of strength at the healing $\operatorname{site}^{10}$. It has been proved that LIPUS can promote formation of the medullary canal and cortex in a gap-healing model, which then leads to earlier restoration of the structural integrity of the healing site ${ }^{11}$. Many clinical studies indicate that LIPUS can enhance the healing of fresh fractures, delayed unions, nonunions, distraction osteogenesis and congenital pseudoarthroses $7,8,12,13$.

In this study, we designed a prospective, randomized study to assess the effect of LIPUS on distal radius fracture, and to investigate the ability of LIPUS to accelerate fracture healing of the distal radius on radiographs.

\section{Methods}

\section{Patient inclusion and exclusion criteria}

The study was approved by the Ethics Committee of Shuguang Hospital and the informed consent was obtained from each patient.

From October 2005 to March 2008, eighty-one outpatients with a fracture at distal radius which were dorsally angulated and displaced were enrolled in this study. The inclusion criteria were (i) fractures involving radiocarpal joint or distal ulnoradial joint, or (ii) involving ulnar styloid process. The exclusion criteria were (i) patients with Smith's fracture and Barton's fracture, and (ii) patients accompanied with systemic diseases such as heart, brain, liver, and kidney.

\section{Experimental design}

The patients' characteristics including sex, age, causes of injury, fracture severity and symptom of pressure on the nerve were recorded. The angulations of palm obliquity, ulna deviation and height of radius were measured by X-ray. The classification of Lidstrom was defined as: $\mathrm{I}^{\circ}$ (no deformity, no dorsal angulation and radius was shortened less than $3 \mathrm{~mm}$ ), $\mathrm{II}^{\circ}$ (light deformity, $1^{\circ}-10^{\circ}$ of dorsal angulation and radius was shortened 3-6 mm), III $^{\circ}$ (mild deformity, $11^{\circ}-15^{\circ}$ of dorsal angulation and radius was shortened 7-12 mm), and $\mathrm{IV}^{\circ}$ (severe deformity, more than $15^{\circ}$ of dorsal angulation and radius was shortened more than $12 \mathrm{~mm}$ ). Patients were closely reduced and immobilized with cast in the position of palmar flexion. All patients were randomly divided into two groups with the random number table: the ultrasound treatment group $(n=41)$ and the control group $(n=40)$. In ultrasound group, a 'window' of $2.5 \mathrm{~cm}$ in diameter was cut on the dorsal side of fracture site. Ultrasonic probe was applied on the fracture site though the window. The ultrasound treatment was given with $15 \mathrm{~min} /$ day with the low-intensity pulsed therapeutic ultrasonic device (Shanghai Dahu Medical Instrument Plant, including the electropult of ultrasound and ultrasonic probe). The intensity of LIPUS was $30 \mathrm{~mW} / \mathrm{cm}^{2}(1.5 \mathrm{MHz}$ frequency and $200 \mu$ s pulse duration). The first time of ultrasound treatment was performed in hospital by doctors, and then patients manipulated the treatment themselves according to instructions given by doctor. The patients took the entopic and lateral X-ray films at a follow-up examination every week. Two weeks later, the patients in the ultrasound group were immobilized with a below-elbow plaster cast, while the patients in the control group were immobilized with plaster support and cast until clinical union of bone. Then functional training was performed on patients directed by doctors.

In order to initial determine the conditions of bone healing, all patients were re-examined by knocking the 2, 3, 4 metacarpal heads of affected hand after around four weeks. If patients felt pain, then immobilization was continued and a reassessment was done one week later. When patients felt no pain, the plaster cast was removed, and then tenderness and abnormal movement was examined by doctor. The fracture was judged as clinical healing when the affected hand could raise $1 \mathrm{~kg}$ levelly for 1 minute in functional test, and the fracture was not obvious according the $\mathrm{X}$-ray film ${ }^{14}$ (the fracture line was faint in X-ray film). The clinical healing time of each patient was defined as the time from fracture to clinical union. The clinical healing time was assessed by three experienced doctors (blinded to the treatment method).

The initial and final X-ray films of each patient were 
captured with Casio digital camera ( 5 million pixels). The grey level of X-ray films were analyzed by the Photoshop software according to a imaging analysis method describe previously ${ }^{15}$. On the anterior posterior (AP) view of the film, an area of $2.0 \times 0.5$ $\mathrm{cm}$ along the fracture line was selected, meanwhile, the mean value of the grey level in the area was investigated by the order of histogram. The selected area of initial film should be closed to the proximal end of the fracture line, and this can reflect the normal grey level of the bone and avoid the error from fracture site overlapped. The selected area of the film after union was just on the fracture line. The films were also assessed by three experienced doctors who were blinded to the treatment method.

The dorsal inclination of the fracture, drift angle of ulna, and height of radius of primary fracture were measured by $\mathrm{X}$-ray film after fracture healing. Then the effect of manipulation was evaluated based upon Steward recommended by Dienst, combining with Aro's measuring method (Table 1).

TABLE 1 - The score chart for reposition accuracy of the distal radius fracture after union.

\begin{tabular}{lcccc}
\hline Graded items & 0 & 1 & 2 & 3 \\
\hline Dorsal inclination $\left(^{\circ}\right)$ & 0 & $1-10$ & $11-14$ & $>14$ \\
Decrease of drift angle of ulna $\left(^{\circ}\right)$ & $0-4$ & $5-9$ & $10-14$ & $>14$ \\
Shortening of radius (mm) & $0-3$ & $4-6$ & $7-11$ & $>11$ \\
\hline
\end{tabular}

Notes: The sum of the three items being 0 was marked perfect, 1-3 good effect, 4-6 improvement, and 7-12 bad effect.

\section{Statistical analysis}

The chi-square test was used for comparing values of binary variables, student $t$-test was used for comparing means of continuous variables, and the Mann Whitney U test was used for comparing distributions of ordinal variables. $P$ value less than 0.05 was considered to be significant.

\section{Results}

Statistics for all patients showed that the average time from fracture to beginning ultrasound treatment was 3.4 days. There was no significant difference $(p<0.05)$ in sex, age, and various parameters relating to fracture between two groups (Table 2). The mean time to clinical fracture-healing was $32.04 \pm 2.58$ days in ultrasound group and $40.75 \pm 5.12$ days in control group. The clinical healing time in the ultrasound group were less than that in the control group. The change of grey level in the ultrasound group was more than that in the control group (Table 3 and Figure 1). Dorsal inclincation and shortening of the radius were similar in two groups ( $\mathrm{p}>0.05$, Tables 4,5$)$.
TABLE 2 - Comparison of the primal data between the two groups.

\begin{tabular}{lccc}
\hline Comparability & $\begin{array}{c}\text { Treatment } \\
\text { group }\end{array}$ & $\begin{array}{c}\text { Control } \\
\text { group }\end{array}$ & $\mathrm{p}$ \\
\hline Sex & 4 & 5 & $>0.05$ \\
Male (n) & 37 & 35 & 0 \\
Female (n) & $67.90 \pm 5.58$ & $65.70 \pm 6.09$ & $>0.05$ \\
Average age (years) & 24 & 21 & $>0.05$ \\
Fracture of & & & \\
processusstyloideus ulnae (n) & 19 & 21 & $>0.05$ \\
Involving radiocarpal & & & \\
articular surface (n) & 21 & 19 & $>0.05$ \\
Involving distal ulnoradial & & & \\
joint (n) & 22 & 20 & $>0.05$ \\
Comminuted fracture (n) & & & $>0.05$ \\
Lidstrom's type $^{\circ}$ & 12 & 8 & \\
I $^{\circ}$ & 4 & 6 & \\
II $^{\circ}$ & 8 & 12 & \\
III $^{\circ}$ & 17 & 14 & \\
IV $^{\circ}$ & & & \\
\hline
\end{tabular}

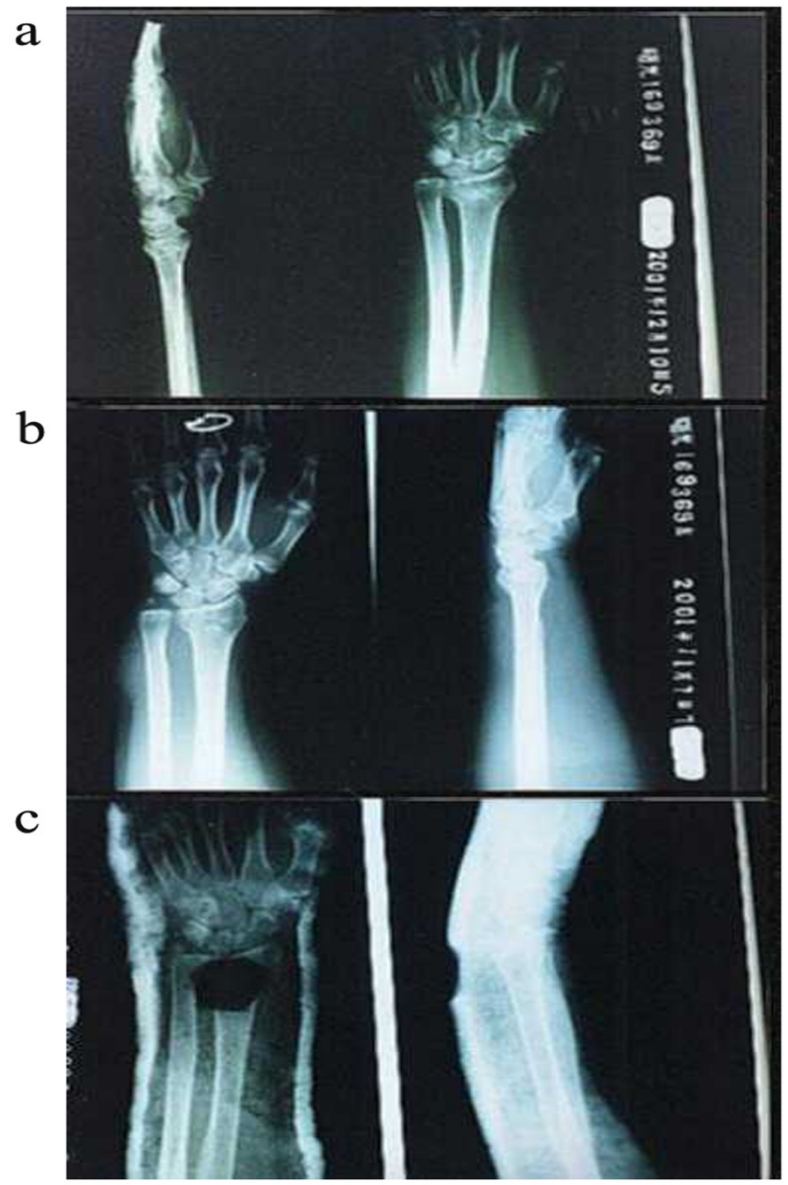

FIGURE 1 - X-ray film in the present study. A. The original X-ray film of a 61year-old male patient; B. After LIPUS therapy for 1 month, bone density at fracture site enhance significantly; C. The cast for LIPUS therapy. 
TABLE 3 - Comparison of the average time of union and the average ratio of the grey level between the two groups.

\begin{tabular}{lccc}
\hline Comparability & $\begin{array}{c}\text { Treatment } \\
\text { group }\end{array}$ & $\begin{array}{c}\text { Control } \\
\text { group }\end{array}$ & $\mathrm{p}$ \\
\hline $\begin{array}{l}\text { The average time of union } \\
\text { (days) }\end{array}$ & $32.04 \pm 2.58$ & $40.75 \pm 5.12$ & $<0.01$ \\
$\begin{array}{l}\text { The average ratio of the } \\
\text { grey level }\end{array}$ & $1.109 \pm 0.147$ & $1.029 \pm 0.096$ & $<0.05$ \\
\hline
\end{tabular}

TABLE 4 - Assessment of the degree of dorsal inclination.

\begin{tabular}{lcccc}
\hline & $0^{\circ}$ & $1-10^{\circ}$ & $11-14^{\circ}$ & $>14^{\circ}$ \\
\hline Treatment group & 10 & 15 & 5 & 1 \\
Control group & 8 & 24 & 8 & 0 \\
\hline
\end{tabular}

TABLE 5 - Assessment of the shortening of the radius.

\begin{tabular}{lcccc}
\hline & $0-3 \mathrm{~mm}$ & $4-6 \mathrm{~mm}$ & $7-11 \mathrm{~mm}$ & $>11 \mathrm{~mm}$ \\
\hline Treatment group & 7 & 26 & 6 & 2 \\
Control group & 5 & 25 & 9 & 1 \\
\hline
\end{tabular}

In the 81 cases of distal radius fracture, 49 cases got good accuracy of reposition, 29 cases showed a little improvement in reposition accuracy and three cases had poor accuracy of reposition. The reposition accuracy of fracture healing was graded and no difference were found in reposition between the two groups $(\mathrm{p}>0.05$, Table 6).

TABLE 6 - Comparison of the reposition accuracy between the two groups.

\begin{tabular}{lccc}
\hline Comparability & Treatment group & Control group & $\mathrm{p}$ \\
\hline Grade & & & $>0.05$ \\
Marked effect & 3 & 2 & \\
Good effect & 23 & 21 & \\
Improvement & 13 & 16 & \\
Bad effect & 2 & 1 & 0 \\
Sum & 41 & 40 & $>0.05$ \\
\hline
\end{tabular}

\section{Discussion}

The histological or biomechanics method could not be used for comparing fracture healing of distal radius in clinical trials. The grey levels of the fracture site were corrected to eliminate error coming from different conditions of taking the X-ray film. The grey level of X-ray film could indirectly reflect the changes of bone mineral density. Thus, we could compare the grey level of X-ray film to assess bone mineral density of fracture site in this study. The result indicated that the bone mineral density in the ultrasound group was statistically higher than that in the control group ( $<<0.05)$, and it meant that LIPUS could promote bone formation at local site.
LIPUS has already been used to promote the fracture healing in both animal fracture models and clinical trials $\mathbf{s}^{7,9,13,16,17}$. Fracture healing involves inflammation, soft callus formation, hard callus formation, and bone remodeling ${ }^{18}$. Several studies indicate that LIPUS can be applied to accelerate the fracture healing by influencing all four stages of fracture healing ${ }^{18-22}$. The mechanical stresses resulting from LIPUS can manipulate the expression and functioning of various cells as well as molecules involved in the fracture healing process. Rawool et al. ${ }^{23}$ found that LIPUS can increase the local blood flow of fracture site promoting the bone union. Tsumaki et al. ${ }^{24}$ demonstrated that LIPUS accelerates callus maturation after opening-wedge high tibial osteotomy by hemicallotasis. LIPUS can stimulate the expression of integrins and facilitates adhesion of osteoblasts at the fracture site ${ }^{20,21}$. In addition, LIPUS upregulate the expression of master transcription factors directing osteogenic differentiation of pluripotent cells including Runx2, Msx2, Dlx5, osterix and bone sialoprotein, which are essential for fracture healing ${ }^{25,26}$. However, fracture healing is very intricate, and many factors could advance or slow the process. Moreover, the udnerlying mechanism by which LIPUS accelerates bone union is not fully understood.

The objective of this study was to evaluate the effect of LIPUS on fracture healing of distal radius. The times $(15 \mathrm{~min} /$ day for at least 12 weeks) to clinical healing in the LIPUS group was significantly shortened compared with that in the control group. This result indicated that LIPUS could increase bone formation at the fracture site (Figure 1) and accelerate the fracture healing of distal radius. In terms of the application of LIPUS to forearm fractures, Kristiansen et al. ${ }^{12}$ perform a randomized, controlled trial of 85 patients with metaphyseal fractures of the distal radius treated with LIPUS. The mean time to fracture healing was significantly reduced by $34 \%$ in the LIPUS group. In the present study, the values of reduction time by LIPUS were $20 \%$ for clinical healing. Moreover, there was no difference in reposition between the two groups $(p>0.05)$ in the present study, and the therapeutic effects of LIPUS were not satisfactory. The possible reasons were not difficult to explore. Firstly, the mean age of patients was more than 60 years and many of them were osteoporotic. Although the reposition efficacy was good initially, the bone might be shorten or translocated during fracture healing process. Secondly, some patients suffered from severe injuries and the fracture was unstable, the fixation with plaster could not maintain the position. In addition, the reposition efficacy was also determined by good reposition at the moment of fracture, firm external fixation, bone mineral density at the fracture and the fracture type. Thus, there was no different in reposition efficacy in the ultrasound treatment group. 
The intensity of therapeutic ultrasonic device was $30 \mathrm{~mW} /$ $\mathrm{cm}^{2}$ in the present study. As a kind of energy and wave, the intensity and frequency are the most important parameters of ultrasound. Moreover, time of treatment have an important influence on the therapeutic effect. In most experiments and clinical studies, the ultrasound (intensity of $30-50 \mathrm{~mW} / \mathrm{cm}^{2}$ ) is used to accelerate fracture healing. It has been indicated that lower intensities of ultrasound therapy is used for fracture healing because the higher intensities may cause tissue damage ${ }^{27}$. Tsai found that the ultrasound with intensity $1.0 \mathrm{~W} / \mathrm{cm}^{2}$ can inhibit rabbit fibula healing ${ }^{28}$. However Yang and colleagues find that the average maximum torque and average torsional stiffness were significantly increase when treated with ultrasound with an intensity of $50 \mathrm{~mW} / \mathrm{cm}^{2,29}$. Watson $\mathrm{T}$ report that the effective dose of LIPUS is lower $\left(30 \mathrm{~mW} / \mathrm{cm}^{2}\right)$ than ultrasound doses used for soft tissue healing ${ }^{30}$. In general, the ultrasound intensities for acute conditions should be between 10 and $30 \mathrm{~mW} / \mathrm{cm}^{2}$, and the intensity is chosen based on the target.

The $0.5-1.5 \mathrm{MHz}$ ultrasound is the most commonly used frequency to accelerate fracture healing in experiments and clinical studies. Tsai prove that $1.5 \mathrm{MHz}$ ultrasound can increase endogenous PGE2 and have the best effect of accelerating bone healing ${ }^{31}$. Wang et al. ${ }^{32}$ suggest that the effect of $1.5 \mathrm{MHz}$ on fracture healing is better than that of $0.5 \mathrm{MHz}$ on fracture healing with biochemical tests. Thus, based on the previous data, the frequency of therapeutic ultrasonic device was $1.5 \mathrm{MHz}$ in our study. Most researchers applied ultrasound 15-20 min daily. The total treatment times were determined according to the fracture site and condition of patients, until fracture healing. However, there were also some limitations in this study, such as small simple size, patients' age, the confirming method for bone healing, and image analysis technique. Thus, a more optimized research is needed for the further investigation.

\section{Conclusions}

Low-intensity pulse ultrasound stimulation therapy was beneficial to bone healing after the fracture of distal radius. LIPUS might provide an early return to activity and work for patients undergoing fracture.

\section{References}

1. Childs SG. Stimulators of bone healing: biologic and biomechanical Orthop Nurs. 2003 Nov-Dec;22(6):421-28. PMID: 14705472.

2. Trock DH. Electromagnetic fields and magnets: investigational treatment for musculoskeletal disorders. Rheum Dis Clin N Am. 2000 Feb;26(1):51-62. PMID: 10680193.

3. Claes LE, Heigele CA, Neidlinger-Wilke C, Kaspar D, Seidl W,
Margevicius KJ, Augat P. Effects of mechanical factors on the fracture healing process. Clin Orthop Relat Res. 1998 Oct;355:S132-S47. PMID: 9917634.

4. Malizos KN, Hantes ME, Protopappas V, Papachristos A. Lowintensity pulsed ultrasound for bone healing: an overview. Injury. 2006 Apr;37(1):S56-S62.

5. Tajali SB, Ebrahimi E, Kazemi S, Bayat M, Azari A, Azordegan F, Kamali M, Hoseinian M. Effects of He-Ne laser irradiation on osteosynthesis. Osteosynthesis Trauma Care. 2003 Aug;11(S 1):17-20.

6. Tajali SB, Houghton P, MacDermid JC, Grewal R. Effects of low-intensity pulsed ultrasound therapy on fracture healing: a systematic review and meta-analysis. Am J Phys Med Rehabil. 2012 April;91(4):349-67. doi: 10.1097/PHM.0b013e31822419ba.

7. Gebauer D, Mayr E, Orthner E, Ryaby JP. Low-intensity pulsed ultrasound: effects on nonunions. Ultrasound Med Biol. 2005 Oct;31(10):1391-402. PMID: 16223643.

8. Nolte PA, van der Krans A, Patka P, Janssen IM, Ryaby JP, Albers GR. Low-intensity pulsed ultrasound in the treatment of nonunions. J Trauma Acute Care Surg. 2001 Oct;51(4):693-703. PMID: 11586161.

9. Rutten S, Nolte PA, Korstjens CM, van Duin MA, Klein-Nulend J. Low-intensity pulsed ultrasound increases bone volume, osteoid thickness and mineral apposition rate in the area of fracture healing in patients with a delayed union of the osteotomized fibula. Bone. 2008 Aug;43(2):348-54. doi: 10.1016/j.bone.2008.04.010.

10. Tobita K, Matsumoto T, Ohashi S, Bessho M, Kaneko M, Ohnishi I. Effect of low-intensity pulsed ultrasound stimulation on gap healing in a rabbit osteotomy model evaluated by quantitative microcomputed tomography-based cross-sectional moment of inertia. J Orthop Sci. 2012 Jul;17(4):470-6. PMID: 22543854.

11. Tobita K, Ohnishi I, Matsumoto T, Ohashi S, Bessho M, Kaneko M, Matsuyama J, Nakamura K. Effect of low-intensity pulsed ultrasound stimulation on callus remodelling in a gap-healing model: evaluation by bone morphometry using three-dimensional quantitative micro-CT. J Bone Joint Surg Br. 2011 Apr;93(4):52530. doi: 10.1302/0301-620X.93B4.25449.

12. Kristiansen TK, Ryaby JP, McCABE J, Frey JJ, Roe LR. Accelerated healing of distal radial fractures with the use of specific, lowintensity ultrasound. A multicenter, prospective, randomized, double-blind, placebo-controlled study. J Bone Joint Surg Br. 1997 Jul;79(7):961-73. PMID: 9234872.

13. Heckman JD, MCCABE J, RNI JJ. By non-invasive, low-intensity pulsed ultrasound. J Bone Joint Surg Am. 1994 Jan;76:26-34. PMID:8288661.

14. Kreder HJ, Hanel DP, McKee M, Jupiter J, McGillivary G, Swiontkowski MF. X-ray film measurements for healed distal radius fractures. J Hand Surg Am. 1996 Jan;21(1):31-9. PMID:8775193.

15. Sakakura CE, Giro G, Gonçalves D, Pereira RMR, Orrico SRP, Marcantonio Jr E. Radiographic assessment of bone density around integrated titanium implants after ovariectomy in rats. Clin Oral Implants Res. 2006 Apr;17(2):134-38. PMID: 16584408.

16. Lai C-H, Chuang C-C, Kuan-Jung Li J, Chen S-C, Hong-Shong Chang W. Effects of ultrasound on osteotomy healing in a rabbit fracture model. Ultrasound Med Biol. 2011 Oct;37(10):1635-43. PMID: 21821345.

17. Azuma Y, Ito M, Harada Y, Takagi H, Ohta T, Jingushi S. Lowintensity pulsed ultrasound accelerates rat femoral fracture healing by acting on the various cellular reactions in the fracture callus. J Bone Miner Res. 2001 Apr;16(4):671-80. PMID: 11315994.

18. Mundi R, Petis S, Kaloty R, Shetty V, Bhandari M. Low-intensity pulsed ultrasound: fracture healing. Indian J Orthop. 2009 Apr;43(2):132. PMID: 19838361.

19. Pounder NM, Harrison AJ. Low intensity pulsed ultrasound for 
fracture healing: a review of the clinical evidence and the associated biological mechanism of action. Ultrasonics. 2008 Aug;48(4):3308. PMID: 18486959.

20. Yang R-S, Lin W-L, Chen Y-Z, Tang C-H, Huang T-H, Lu B-Y, Fu W-M. Regulation by ultrasound treatment on the integrin expression and differentiation of osteoblasts. Bone. 2005 Feb;36(2):276-83. PMID: 15780953.

21. Tang C-H, Yang R-S, Huang T-H, Lu D-Y, Chuang W-J, Huang T-F, $\mathrm{Fu} \mathrm{W}-\mathrm{M}$. Ultrasound stimulates cyclooxygenase-2 expression and increases bone formation through integrin, focal adhesion kinase, phosphatidylinositol 3-kinase, and Akt pathway in osteoblasts. Mol Pharmacol. 2006 Jun;69(6):2047-57. PMID: 16540596.

22. Sena K, Leven RM, Mazhar K, Sumner DR, Virdi AS. Early gene response to low-intensity pulsed ultrasound in rat osteoblastic cells. Ultrasound Med Biol. 2005 May;31(5):703-8. PMID: 15866420.

23. Rawool NM, Goldberg BB, Forsberg F, Winder AA, Hume E. Power Doppler assessment of vascular changes during fracture treatment with low-intensity ultrasound. J Ultrasound Med. 2003 Feb;22(2):145-53. PMID: 12562119.

24. Tsumaki N, Kakiuchi M, Sasaki J, Ochi T, Yoshikawa H. Lowintensity pulsed ultrasound accelerates maturation of callus in patients treated with opening-wedge high tibial osteotomy by hemicallotasis. J Bone Joint Surg. 2004 Nov;86(11):2399-405. PMID: 15523009.

25. Khan Y, Laurencin CT. Fracture repair with ultrasound: clinical and cell-based evaluation. J Bone Joint Surg. 2008 Feb;90(Supplement 1):138-44. PMID: 18292369.

26. Takayama T, Suzuki N, Ikeda K, Shimada T, Suzuki A, Maeno M, Otsuka K, Ito K. Low-intensity pulsed ultrasound stimulates osteogenic differentiation in ROS 17/2.8 cells. Life Sci. 2007 Feb;80(10):965-71. PMID: 17174343.

27. Dyson M. Role of ultrasound in wound healing. Kloth LC, Miller KH. Wound healing. Philadelphia: FA Davis; 1990. p.259-85.

28. Tsai C-L, Chang WH, Liu T-K, Song G-M. Ultrasound can affect bone healing both locally and systemically. Chin J Physiol. 1991;34(2):213. PMID: 1959440.

29. Yang KH, Parvizi J, Wang SJ, Lewallen DG, Kinnick RR, Greenleaf JF, Bolander ME. Exposure to low-intensity ultrasound increases aggrecan gene expression in a rat femur fracture model. J Orthop Res. 1996 Sep;14(5):802-9. PMID: 8893775.

30. Watson T, Young SR. Therapeutic ultrasound. Electrotherapy: evidence based practice. Edinburgh: Churchill LivingstoneElsevier; 2008
31. Tsai C-L, Chang WH, Liu T-K, Song G-M. Ultrasonic effect on fracture repair and prostaglandin E2 production. Chin J Physiol. 1992;35(1):27. PMID: 1424953.

32. Wang SJ, Lewallen DG, Bolander ME, Chao E, Ilstrup DM, Greenleaf JF. Low intensity ultrasound treatment increases strength in a rat femoral fracture model. J Orthop Res. 1994 Jan;12(1):40-7. PMID: 8113941.

\section{Acknowledgement}

To all the authors who contributed to the research and all the supports to our study.

\section{Correspondence:}

Yong Kuang

Department of Orthopaedics, Shuguang Hospital Affiliated

Shanghai TCM University

No.528 Zhangheng Road, Shanghai 200021, China

Phone: +8602161326326

Fax: +8602120256699

kuangyongpll@hotmail.com

Received: June 19, 2014

Review: Aug 18, 2014

Accepted: Sep 22, 2014

Conflict of interest: none

Financial sources: National TCM Traumatology and Orthopedics Key Discipline (100508), Shanghai leading talent project (041), key project of shanghai science and technology commission (09dZ1973800), Shanghai Health Bureau in pharmaceutical research special (2014LP096A), The Shanghai TCM genre the Shi's SHANGKE heritage base project (ZYSNXD-CC-HPGC-JDD-001).

${ }^{1}$ Research performed at Institution of Shuguang Hospital, Shanghai TCM University, China. 